\title{
Operational Performance Evaluation of Korean Major Container Terminals
}

\author{
Bo $L U^{\dagger} \cdot$ Nam-Kyu Park* $^{*}$ \\ † Department of Distribution Management, TongMyong University, Busan 608-711, Korea \\ *Faculty of Port Logistics, TongMyong University, Busan 608-711, Korea
}

\begin{abstract}
As the competition among the container terminals in Korea has become increasingly fierce, every terminal is striving to increase its investments constantly and lower its operational costs in order to maintain the competitive edge and provide satisfactory services to terminal users. The unreasoning behavior, however, has induced that substantial waste and inefficiency exists in container terminal production. Therefore, it is of great importance for the terminal to know whether it has fully used its existing infrastructures and that output has been maximized given the input. From this perspective, data envelopment analysis (DEA) provides a more appropriate benchmark. This study applies three models of DEA to acquire a variety of analytical results about the operational efficiency to the Korean container terminals. According to efficiency value analysis, this study first finds the reason of inefficiency. It is followed by identification of the potential areas of improvement for inefficient terminals by applying slack variable method and giving the projection results. Finally, return to scale approach is used to assess whether each terminal is in a state of increasing, decreasing, or constant return to scale. The results of this study can provide terminal managers with insight into resource allocation and optimization of the operating performance.
\end{abstract}

Key words : Efficiency, Korean major container terminals, Data envelopment analysis, Throughput, Performance

\section{Introduction}

In recent years, with rapid expansion of global business and international trade, one distinctive feature of the current container terminal industry is that competition among container terminals is more intensive than previously (Liu, 1995; Tongzon and Heng, 2005; Yap and Lam, 2005).

To maintain its competitiveness in such competitive condition, Kevin Cullinane et al. (2006) claimed container terminals have to invest heavily in sophisticated equipment or in dredging channels to accommodate the most advanced and largest container ships in order to facilitate cost reductions for the container shipping industry.

It is important to note, however, that pure physical expansion is constrained by a limited supply of available land, especially for urban centre terminals, and escalating environmental concerns. In addition, the excessive and inappropriate investment also can induce the phenomenon of inefficiency and wasting of resources. In this context, improving the productive efficiency of container terminals (Le-Griffin et al., 2006) appears to be the viable solution.

Realizing the facts, Korean port authorities like BPA, IPA, and UPA have shown strong interest in efficient terminal management. Thus, they are continually searching for strategies to meet growing demands by utilizing their resources reasonably.

For a container terminal, productivity performance makes significant contribution to the prospects of survival and competitive advantage. Traditionally, the productivity of container terminals has been variously evaluated by numerous attempts at calculating and seeking to improve or optimize the operational productivity of cargo-handling at berth and in the container yard (Kim, 1997; Kim and Bae, 1998; Kim and Kim, 1998; Kim and Kim, 1999; Robinson, 1999; Avriel et al., 2000; Wilson and Roach, 2000; Chu and Huang, 2002).

If Korean container terminals can conduct effective evaluation of their operational performance in a globally competitive environment, it will provide valuable information for terminal management in their attempts to establish competitive strategies and to improve their resource efficient utilization.

From this perspective, data envelopment analysis model provides a more appropriate benchmark for the container terminal. The aim of this study is to evaluate the operational performance of container terminals which can be calculated by relative productivity, and defined as how to minimize inputs while producing a given level of output, or how to maximize outputs while using no greater quantity of any of the individual inputs within a given set of inputs, by

\footnotetext{
† Corresponding author, lubo_documents@hotmail.com 051) 629-1861

* nkpark@tu.ac.kr 051)629-1861
} 
applying with DEA-CCR, DEA-BCC, and DEA-Super Efficiency, three models to acquire a variety of analytical results about the productivity efficiency for thirteen Korean major container terminals.

According to efficiency value analysis, this study first finds the reason of inefficiency. It is followed by identification of the potential areas of improvement for inefficient terminals by applying slack variable method which includes the projection analysis. Finally, return to scale approach is used to assess whether each terminal is in a state of increasing, decreasing, or constant return to scale.

The paper is structured as follows: after the introductory section of chapter 1, there will be followed by the description of three data envelopment analysis (DEA) models. In so doing, the three main approaches to applying DEA to analyze data are included in chapter 2 . The required input and output variables are defined and the data that has been collected is described. Efficiency estimates of the study object are derived in chapter 3. Finally, conclusions are drawn in chapter 4.

\section{Research method}

\subsection{Data envelopment analysis (DEA)}

DEA can be roughly defined as a non-parametric method of measuring the efficiency of a Decision Making Unit (DMU) with multiple inputs and/or multiple outputs. This is achieved by constructing a single 'virtual' output to a single 'virtual' input without pre-defining a production function. The term DEA and the CCR model were first coined in Charnes et al. (1978) and were followed by a phenomenal expansion of DEA in terms of its theory, methodology and application over the last few decades. The influence of the CCR paper is reflected in the fact that by 1999 it had been cited over 700 times (Forsund and Sarafoglou, 2002).

Among the models in the context of DEA, the two DEA models, named CCR (due to Charnes et al., 1978) and BCC models (due to Banker et al., 1984) have been widely applied. The CCR model assumes constant returns to scale so that all observed production combinations can be scaled up or down proportionally. The BCC model, on the other hand, allows for variable returns to scale and is graphically represented by a piecewise linear convex frontier.

Because the CCR model gives a value of 1 for all efficient DMUs, it is unable to establish any further distinctions among the efficient DMUs. Andersen and Petersen, therefore, presented a new DEA model, DEA-Super
Efficiency model. This model removes an efficient DMU, and then estimates the production frontier again; this provides a new efficiency value for the efficient DMU that had previously been removed. The new efficiency value can thus be greater than 1 . However, if an inefficient DMU is removed, the original production frontier does not change. Therefore, the efficiency values of inefficient DMUs do not change in the DEA-Super Efficiency model.

In other words, the two basic models of DEA (i.e. CCR and BCC models) are used to provide the efficiency values for self-appraisal of terminal operational performance. The DEA-Super Efficiency model is used to make further distinctions among the efficient DMUs since they all have efficiency values of 1 in the CCR model. Thus, the varied and complementary information can be extracted from these three models to provide a more complete and comprehensive performance evaluation.

The DEA methodology has been applied to the evaluation of terminal performance in the previous literature. For example, Roll and Hayuth (1993) probably represents the first work to advocate the application of the DEA technique to the terminals context. However, it remains a purely theoretical exposition, rather than a genuine application. For the period 1990 - 1999, Itoh (2002) conducted a DEA window analysis using panel data relating to the eight international container ports in Japan. Tongzon (2001) uses both DEA-CCR and DEA-Additive models to analyze the efficiency of four Australian and 12 other international container ports for 1996. Barros and Athanassiou (2004) apply DEA to the estimation of the relative efficiency of a sample of Portuguese and Greek seaports.

However, most previous studies have adopted two basic models of DEA (the CCR model and the BCC model) to obtain aggregate efficiency, pure technical efficiency and scale efficiency. In contrast, this study also adopts DEA-Super Efficiency to acquire useful and complementary information about terminals.

In this study, the DEA model includes three types of analysis. With respect to the efficiency value analysis, when technical efficiency is less than 1 , that is technical inefficient, this means that the efficiency of the inputs and output being used is not appropriate, and that it is necessary to decrease input or/and increase output. However, when the scale efficiency is less than 1 , that is scale inefficient, it means that the operational scale is not achieving an optimal value, and that the operational scale should be enlarged or reduced (based on the return to scale). In addition, it is 
possible to compare the technical efficiency value with the scale efficiency value, with the smaller value of the two indicating the major cause of inefficiency. Finally, the slack variable analysis handles the utilization rate of input and output variables. It does this by assessing how to improve the operational performance of inefficient DMUs by indicating how many inputs to decrease, and/or how many outputs to increase, so as to render the inefficient DMUs efficient. This facilitates an overall understanding of which input variable is more critical for efficiency improvement ( $\mathrm{L}$. C. LIN, 2007). In summary, the flow process of multiple DEA analyses can be depicted as shown in figure 1 .

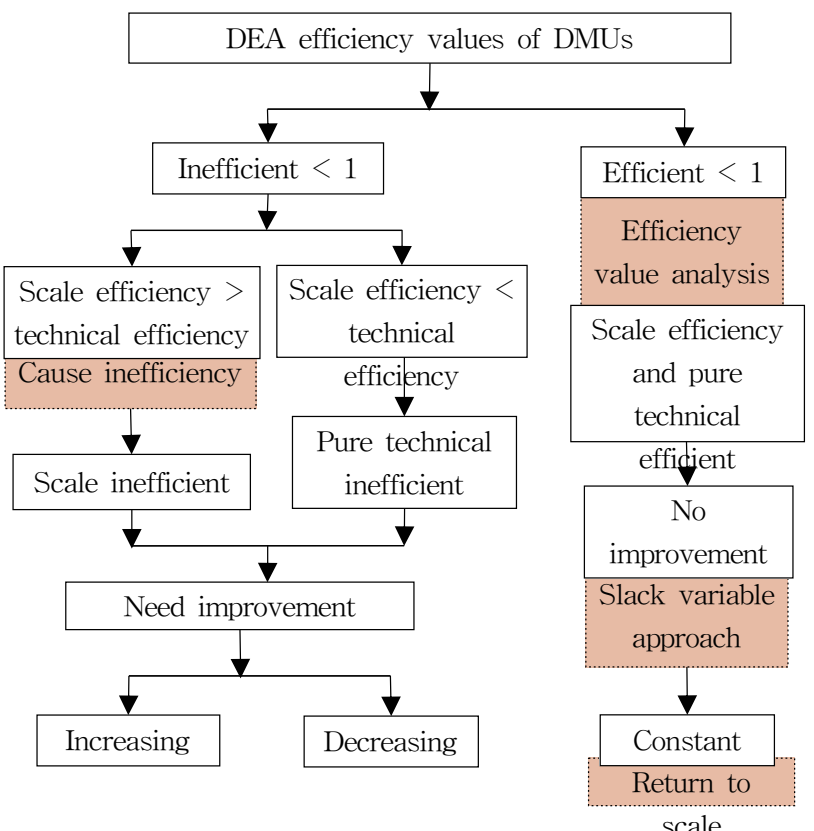

Fig. 1 Flow process of DEA analysis

Source: Modified by L. C. Lin and C. C. Tseng, 2007

\subsection{Research procedure}

The research procedure of this study is summarized in figure 2. After the selection of container terminals, the output variable for the study should be selected firstly. Drawing on the literature review, site survey \& interview, and Brainstorming to eliminate the duplication factors, the initial inputs variables can be chosen.

Then, in order to provide a more comprehensive picture of research, and for the purpose of finding the operational efficiency value, an exploration composed of the CCR, BCC and Super-efficiency DEA models and three analytical approaches which include efficiency value analysis, slack variable method and return to scale approach have been applied. After that, the evaluation results and suggestions will be given.

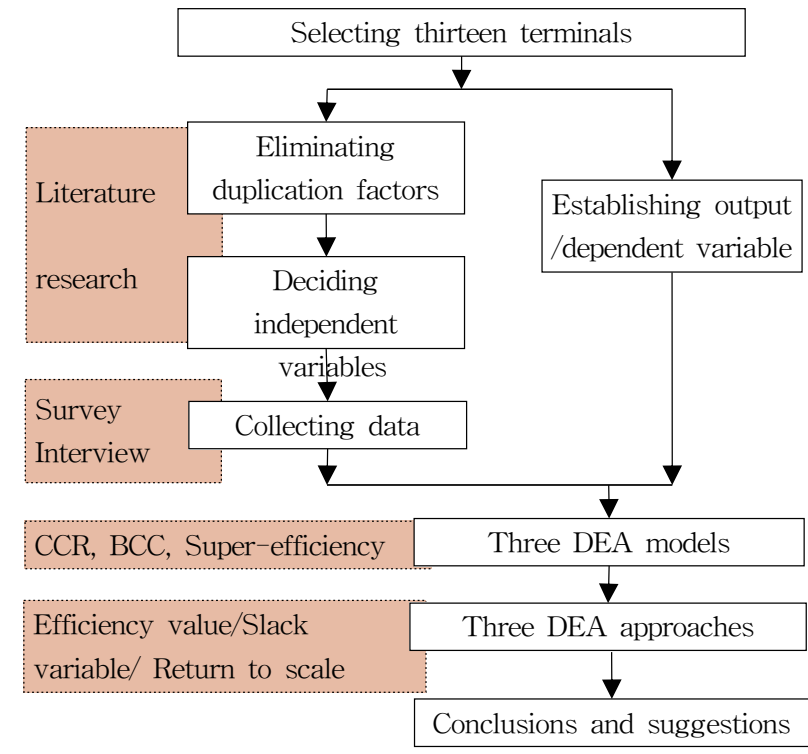

Fig. 2 Research procedure

Source: Authors of the original source

\section{Result analysis}

\subsection{Data collection and definitions of variables}

Because it is difficult to acquire data on integral scale, most of the previous documents have focused on the evaluation of several major terminals over the years. For doing a typical and deep analysis, the object of study comprises the thirteen Korean major container terminals, almost contain all of the Korean major container terminals, including KBCT, HBCT, INTERGIS, Hanjin, UTC terminal in Busan port, KIT2-2, KX3-1, GICT1, DBE2-1 terminal in Gwangyang port, ICT, SGCT terminal in Incheon port, JUCT terminal in Ulsan port and PCTC terminal in Pyeongtaek port. When June 20th, 2009, the questionnaire has been made such as table 1 and sent to the relative departments of 13 container terminals, after receiving the questionnaire answers. The researchers of this study went to the 13 terminals to confirm the accuracy of the data during July 25th, 2009 to August 30th, 2009.

With respect to definitions of variables, a thorough discussion of the importance, difficulties and potential impact of variable definition can be found in (Song et al, 2003), and the main criterion of this study for choosing variables can be summarized as that the input and output variables should reflect the actual objectives and process of container terminal production as accurately as possible. Because the most container terminals rely heavily upon sophisticated equipment and information technology, rather than being intensive labour. 
Operational Performance Evaluation of Korean Major Container Terminals

Table 1 Questionnaire of study

\begin{tabular}{|c|c|c|c|c|c|c|c|}
\hline & & & \multicolumn{3}{|c|}{ Berth } & \multirow{3}{*}{\multicolumn{2}{|c|}{$\begin{array}{c}\text { Throughput } \\
\text { (TEU) }\end{array}$}} \\
\hline \multirow{2}{*}{$\begin{array}{c}\text { Water } \\
\text { Depth }(\mathrm{m})\end{array}$} & \multirow{2}{*}{\multicolumn{2}{|c|}{\begin{tabular}{c|} 
Berth \\
Length $(\mathrm{m})$
\end{tabular}}} & \multirow{2}{*}{ Berth No. } & \multicolumn{2}{|c|}{ Crane No. } & & \\
\hline & & & & Type & No. & & \\
\hline \multicolumn{8}{|c|}{ Yard } \\
\hline \multirow{2}{*}{$\begin{array}{l}\text { Yard } \\
\text { Area } \\
\left(\mathrm{m}^{2}\right)\end{array}$} & \multirow{2}{*}{$\begin{array}{l}\text { CFS } \\
\text { Area } \\
\left(m^{2}\right)\end{array}$} & \multicolumn{4}{|c|}{ Crane No. } & \multicolumn{2}{|c|}{ Gate No. } \\
\hline & & RTG & \begin{tabular}{l|l|} 
C & RMGC \\
\end{tabular} & RS & YT & In & Out \\
\hline & & & & & & & \\
\hline
\end{tabular}

Therefore, in order to determine the input variables, the adopted initial variables in the study are discovered through an abundant literature review, discussion with experts working in container ports for more than 20 years and brainstorming, almost factors that relevant to terminal operation are to be considered such as terminal facilities like yard area, number of berth, water depth, length of berth, gate, rail station etc., and port equipment like $\mathrm{Y} / \mathrm{T}, \mathrm{Q} / \mathrm{C}$, RTGC, RMGC, reach stacker, top handler and folk lifter etc.

However, in the light of concerning the process of container terminal production lie on crucially the efficient utilization of infrastructures and facilities. The yard area, the quantities of quay crane, yard crane, yard tractor, berth length, and water depth have been deemed to be the most suitable input variables.

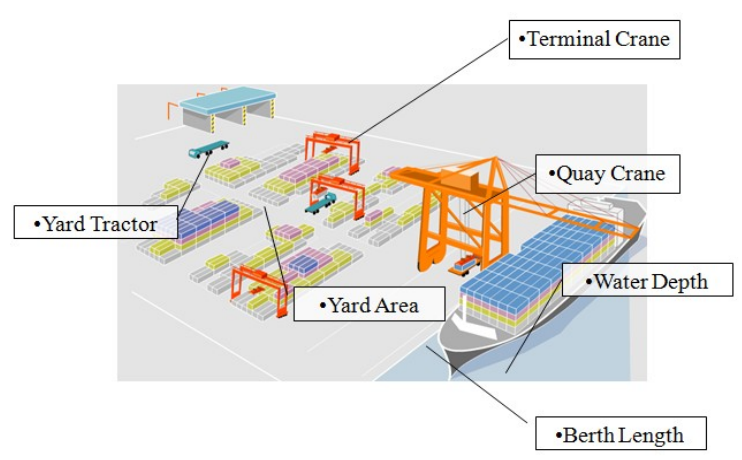

Fig. 3 Definitions of input variables

Source: Authors of the original source

With regard to the output variable, container throughput is unquestionably the most important and widely accepted indicator of container terminal output. Almost all previous studies treat it as an output variable, because it closely relates to the need for cargo-related facilities and services and is the primary basis upon which container terminals are compared, especially in assessing their relative size, investment magnitude or activity levels. Most importantly, it also forms the basis for the revenue generation of a container port or terminal (Kevin Cullinane et al, 2005).
Synthesizing the former research, in this study, the output variable is defined as throughput.

Table 2 Data collection of Korean major terminals

\begin{tabular}{|c|c|c|c|c|}
\hline \multirow{2}{*}{$\begin{array}{l}\text { Variable } \\
\text { Terminaks }\end{array}$} & \multicolumn{4}{|c|}{ Inputs } \\
\hline & $\begin{array}{l}\text { Yard area } \\
\text { per berth }\end{array}$ & $\begin{array}{l}\text { QC per } \\
\text { berth }\end{array}$ & $\begin{array}{l}\text { TC per } \\
\text { berth }\end{array}$ & $\begin{array}{l}\text { YT per } \\
\text { berth }\end{array}$ \\
\hline \multicolumn{5}{|l|}{ Busan } \\
\hline KBCT & 163518 & 2.8 & 9.2 & 14.6 \\
\hline HBCT & 92562 & 2.8 & 6.8 & 12.6 \\
\hline INTERGIS & 41777 & 4 & 19 & 24 \\
\hline Hanjin & 52500 & 2.5 & 6.5 & 11.5 \\
\hline UTC & 78000 & 3.3 & 10 & 16 \\
\hline \multicolumn{5}{|l|}{ Gwangyang } \\
\hline KIT2-2 & 108203 & 2.5 & 4.75 & 5 \\
\hline KX3-1 & 140700 & 3 & 8 & 12 \\
\hline GICT1 & 198300 & 2.5 & 8.5 & 11.5 \\
\hline DBE2-1 & 125000 & 2 & 5 & 15 \\
\hline \multicolumn{5}{|l|}{ Incheon } \\
\hline ICT & 56533 & 3 & 6.5 & 7 \\
\hline SGCT & 12663 & 1.5 & 3.5 & 4 \\
\hline \multicolumn{5}{|l|}{ Ulsan } \\
\hline JUCT & 84275 & 3 & 7 & 7 \\
\hline \multicolumn{5}{|l|}{ Pyeongtaek } \\
\hline PCTC & 39970 & 2 & 6 & 10 \\
\hline Average & 94661 & 2.8 & 8.8 & 12.8 \\
\hline \multirow{2}{*}{$\begin{array}{l}\text { Variable } \\
\text { Terminals }\end{array}$} & \multicolumn{2}{|c|}{ Inputs } & \multirow{2}{*}{\multicolumn{2}{|c|}{$\begin{array}{c}\text { Output } \\
\begin{array}{c}\text { Throughput per } \\
\text { berth }\end{array}\end{array}$}} \\
\hline & $\begin{array}{l}\text { Berth } \\
\text { Length }\end{array}$ & $\begin{array}{l}\text { Water } \\
\text { depth }\end{array}$ & & \\
\hline \multicolumn{5}{|l|}{ Busan } \\
\hline KBCT & 300 & 15 & \multicolumn{2}{|c|}{468353} \\
\hline HBCT & 289.4 & 12.5 & \multicolumn{2}{|c|}{423817} \\
\hline INTERGIS & 350 & 15 & \multicolumn{2}{|c|}{768459} \\
\hline Hanjin & 300 & 13.4 & \multicolumn{2}{|c|}{263830} \\
\hline UTC & 333.3 & 11 & \multicolumn{2}{|c|}{284867} \\
\hline \multicolumn{5}{|l|}{ Gwangyang } \\
\hline KIT2-2 & 300 & 15.5 & \multicolumn{2}{|c|}{116056} \\
\hline KX3-1 & 350 & 15 & \multicolumn{2}{|c|}{158359} \\
\hline GICT1 & 350 & 15 & \multicolumn{2}{|c|}{267400} \\
\hline DBE2-1 & 350 & 16 & \multicolumn{2}{|c|}{46625} \\
\hline \multicolumn{5}{|l|}{ Incheon } \\
\hline ICT & 300 & 14 & \multicolumn{2}{|c|}{180994} \\
\hline SGCT & 203.5 & 11 & \multicolumn{2}{|c|}{232267} \\
\hline \multicolumn{5}{|l|}{ Ulsan } \\
\hline JUCT & 220 & 13 & \multicolumn{2}{|c|}{211652} \\
\hline Pyeongtaek & & & & \\
\hline PCTC & 240 & 11 & & \\
\hline Average & 307.3 & 13.9 & & \\
\hline
\end{tabular}

Source: First-hand data collected by authors

\subsection{Standardization of Output and Input Variables}

In order to gain the accurate performance of container terminals, the value of input and output variables should be standardized.

Therefore, this study defines the inputs and output of each container terminal at the level of per berth which is applied with the published data by inner report, except the input of water depth still keeping the actual values. The 
standardization formula can be summarized as:

$$
\frac{\text { Inputs / Output Variable }}{\text { Berth Number }}=\text { Input/Output Variable per berth }
$$

\subsection{Efficiency results derived from DEA models}

As with using the data of thirteen Korean container terminals by applying with DEA approaches, for proving the production function of container terminals exhibits either constant or variable returns to scale, the DEA-CCR and DEA-BCC models are chosen from among several DEA models to analyze terminal production. In addition, for ordering the efficiency terminals, the DEA-Super efficiency is adopted.

The efficiency analytical results for container terminals are summarized in table 3 , and the following observations can be made. The column and row totals represent, respectively, the efficiency value of each terminal and the condition of return to scale in 2008 year.

It is clear from table 3 that, the DEA-CCR model yields lower average efficiency estimates than the DEA-BCC model, with respective average values of 0.633 and 0.792 , where an index value of 1.000 equates to perfect (or maximum) efficiency. The Super-efficiency model was utilized to reinforce the discriminatory power of the CCR model. INTERGIS has the best performance among these thirteen terminals. SGCT and HBCT terminal ranked as the second and third best in this model respectively. The scores are more than 1.100, with these efficiency values far exceeding that of other terminals.

By using of efficiency value analysis, slack variable approach, and return to scale method, the analytical results can be summarized as:

Firstly, the aggregate efficiency value acquired from the CCR model of HBCT, INTERGIS, and SGCT are all equal to 1. The efficiency values of other container terminals in 2008 are less than 1, which indicate that they were relatively inefficient container terminals. The pure technical efficiency value obtained from the $\mathrm{BCC}$ model represents the efficiency in terms of the usage of input resources. If a terminal has an efficiency value equal to 1 in the CCR model, the value of its pure technical efficiency would also be equal to 1 . However, if the efficiency value on the CCR model is less than 1, a comparison could be made between the pure technical efficiency value and the scale efficiency value, thus allowing a judgement to be made about whether the inefficiency is caused by an inefficient application of input resources or an inappropriate production scale.

Table 3 Efficiency under three DEA models

\begin{tabular}{|c|c|c|c|}
\hline \multirow{2}{*}{$\begin{array}{l}\text { Variable } \\
\text { Terminals }\end{array}$} & \multicolumn{3}{|c|}{ Efficiency Score } \\
\hline & CCR efficiency & Super efficiency & Rank \\
\hline Intergis & 1.000 & 2.095 & 1 \\
\hline SGCT & 1.000 & 1.791 & 2 \\
\hline HBCT & 1.000 & 1.179 & 3 \\
\hline KBCT & 0.996 & 0.996 & 4 \\
\hline JUCT & 0.685 & 0.685 & 5 \\
\hline Hanjin & 0.684 & 0.684 & 6 \\
\hline GICT1 & 0.624 & 0.624 & 7 \\
\hline UTC & 0.607 & 0.607 & 8 \\
\hline $\mathrm{ICT}$ & 0.529 & 0.529 & 9 \\
\hline KIT2-2 & 0.400 & 0.400 & 10 \\
\hline KX3-1 & 0.347 & 0.347 & 11 \\
\hline PCTC & 0.205 & 0.205 & 12 \\
\hline DBE2-1 & 0.148 & 0.148 & 13 \\
\hline Average & 0.633 & \multirow{2}{*}{$\begin{array}{r}0.792 \\
\text { efficiency }\end{array}$} & \\
\hline \multirow[b]{2}{*}{$\begin{array}{l}\text { Kariable } \\
\text { Terminaks }\end{array}$} & Reasons of inefficiency & & \multirow[b]{2}{*}{$\begin{array}{c}\text { Return to } \\
\text { scale }\end{array}$} \\
\hline & BCC efficiency & $\begin{array}{c}\text { Scale } \\
\text { efficiency }\end{array}$ & \\
\hline \multicolumn{4}{|l|}{ Busan } \\
\hline KBCT & 1.000 & 0.996 & Decreasing \\
\hline HBCT & 1.000 & 1.000 & Constant \\
\hline Intergis & 1.000 & 1.000 & Constant \\
\hline Hanjin & 0.832 & 0.822 & Increasing \\
\hline UTC & 1.000 & 0.607 & Increasing \\
\hline \multicolumn{4}{|l|}{ Gwangyang } \\
\hline KIT2-2 & 0.800 & 0.500 & Increasing \\
\hline KX3-1 & 0.733 & 0.473 & Increasing \\
\hline GICT1 & 0.747 & 0.835 & Increasing \\
\hline DBE2-1 & 0.750 & 0.197 & Increasing \\
\hline \multicolumn{4}{|l|}{ Incheon } \\
\hline ICT & 0.786 & 0.673 & Increasing \\
\hline SGCT & 1.000 & 0.100 & Constant \\
\hline \multicolumn{4}{|l|}{ Ulsan } \\
\hline JUCT & 0.925 & 0.741 & Increasing \\
\hline \multicolumn{4}{|l|}{ Pyeongtaek } \\
\hline PCTC & 1.000 & 0.205 & Increasing \\
\hline Average & 0.890 & 0.627 & \\
\hline
\end{tabular}

All of the pure technical efficiency values of KBCT, HBCT, INTERGIS, UTC, SGCT, and PCTC are equal to 1. The technical efficiency values of other container terminals are less than 1, thus indicating that they would need to improve their usage of resources. Among these, KX3-1 has the least pure technical efficiency value.

Secondly, according to the results of return to scale, HBCT, INTERGIS and SGCT were relatively efficient container terminals and had constant return to scale. In addition, apart from constant return to scale, Hanjin, UTC, KIT2-2, KX3-1, GICT1, DBE2-1, ICT, JUCT and PCTC were in a state of increasing return to scale; only KBCT was decreasing return to scale in 2008. 
Table 4 Slack variable analysis results

\begin{tabular}{|c|c|c|c|}
\hline \multirow{2}{*}{$\begin{array}{l}\text { Variable } \\
\text { Terminats }\end{array}$} & \multicolumn{3}{|c|}{ Inputs } \\
\hline & Yard area/berth & QC per berth & TC per berth \\
\hline \\
\hline KBCT & 115623.6 & 0 & 0 \\
\hline \multicolumn{4}{|l|}{ HBCT } \\
\hline \multicolumn{4}{|l|}{ Intergis } \\
\hline Hanjin & 0 & 0.03 & 0 \\
\hline UTC & 13488.61 & 0.36 & 0 \\
\hline \multicolumn{4}{|c|}{ Gwangyang } \\
\hline KIT2-2 & 36925.04 & 0.25 & 0.15 \\
\hline KX3-1 & 27281 & 0.05 & 0 \\
\hline GICT1 & 109264.6 & 0 & 0 \\
\hline DBE2-1 & 15970.5 & 0 & 0 \\
\hline \multicolumn{4}{|l|}{ Incheon } \\
\hline ICT & 20047.35 & 0.47 & 0.31 \\
\hline \multicolumn{4}{|l|}{ SGCT } \\
\hline \multicolumn{4}{|l|}{ Ulsan } \\
\hline JUCT & 46242.17 & 0.79 & 0.81 \\
\hline \multicolumn{4}{|l|}{ Pyeongtaek } \\
\hline PCTC & 1389.23 & 0 & 0 \\
\hline Average & 29710.16 & 0.15 & 0.09 \\
\hline \multirow{2}{*}{$\begin{array}{l}\text { Variable } \\
\text { Terminats }\end{array}$} & \multicolumn{3}{|c|}{ Inputs } \\
\hline & YT per berth & Berth length & Water depth \\
\hline \multicolumn{4}{|l|}{ Busan } \\
\hline KBCT & 1.95 & 0 & 0.81 \\
\hline \multicolumn{4}{|l|}{ HBCT } \\
\hline \multicolumn{4}{|l|}{ Intergis } \\
\hline Hanjin & 1.18 & 14.27 & 0 \\
\hline UTC & 0.98 & 47.12 & 0 \\
\hline \multicolumn{4}{|c|}{ Gwangyang } \\
\hline KIT2-2 & 0 & 18.24 & 0.7 \\
\hline KX3-1 & 0 & 11.32 & 0 \\
\hline GICT1 & 0.72 & 39.95 & 0.39 \\
\hline DBE2-1 & 1.36 & 12.63 & 0.27 \\
\hline \multicolumn{4}{|l|}{ Incheon } \\
\hline ICT & 0 & 17.74 & 0 \\
\hline \multicolumn{4}{|l|}{ SGCT } \\
\hline \multicolumn{4}{|l|}{ Ulsan } \\
\hline JUCT & 0 & 0 & 1.18 \\
\hline \multicolumn{4}{|l|}{ Pyeongtaek } \\
\hline PCTC & 0.36 & 2.88 & 0 \\
\hline Average & 0.50 & 12.63 & 0.26 \\
\hline
\end{tabular}

Finally, the slack variable analysis showed, in table 4, that HBCT, INTERGIS, Hanjin, SGCT and PCTC had been relatively efficient; their ratios of input variables to output variable were appropriate, and they were capable of applying their input resources effectively to achieve enhanced efficiency. In contrast, KBCT, UTC, KIT2-2, KX3-1, GICT1, DBE2-1, ICT and JUCT were relatively inefficient as a result of inappropriate application of input resources.

Furthermore, in these cases, an inappropriate production scale is the cause of the inefficiency of KBCT, KIT2-2, KX3-1, DBE2-1, ICT and JUCT; while UTC and GICT1 were caused by technical inefficiency. The results indicated that main inefficient reason of Korean container terminals should adjust the yard area and increase the throughput. The specific analysis results have been summarized as table 5.

Table 5 Implication of analysis

\begin{tabular}{|c|c|c|}
\hline \multicolumn{2}{|c|}{ Main inefficient reason } & Suggestions \\
\hline \multicolumn{3}{|c|}{ Busan } \\
\hline KBCT & Scale inefficiency & Focus on production scale \\
\hline HBCT & N.A. & Constant \\
\hline Intergis & N.A. & Constant \\
\hline Hanjin & Scale inefficiency & Focus on production scale \\
\hline UTC & Technical inefficiency & Focusing on operation \\
\hline \multicolumn{3}{|c|}{ Gwangyang } \\
\hline KIT2-2 & Scale inefficiency & Focus on production scale \\
\hline KX3-1 & Scale inefficiency & Focus on production scale \\
\hline GICT1 & Technical inefficiency & Focus on operation \\
\hline DBE2-1 & Scale inefficiency & Focus on production scale \\
\hline \multicolumn{3}{|l|}{ Incheon } \\
\hline ICT & Scale inefficiency & Focus on production scale \\
\hline SGCT & N.A. & Constant \\
\hline \multicolumn{3}{|l|}{ Ulsan } \\
\hline JUCT & Scale inefficiency & Focus on production scale \\
\hline \multicolumn{3}{|c|}{ Pyeongtaek } \\
\hline PCTC & Scale inefficiency & Focus on production scale \\
\hline \multicolumn{3}{|c|}{ Technical inefficiency : Inefficient application of input resources } \\
\hline Scale ine & iciency: Inappropriate $\mathrm{p}$ & duction scale \\
\hline
\end{tabular}

After finding out the inefficient reasons, the inefficient terminal should make an adjustment to reach efficient performance. By applying with the projection analysis, this study can identify the optimal benchmark of the quantities of input and output variables. The results has been summarized on table 6.

\section{Conclusions}

For container terminals in the competitive circumstances, efficiency is an important concept and concerned with how to use limited resources more economically for any sort of production. As a benchmarking approach to study efficiency, DEA enables a container terminal to evaluate its performance from each other in DMUs. By doing this, the possible waste of resources and the industry best practice can be identified. By using a range of DEA models, this study has evaluated the thirteen Korean container terminals, and in the process has acquired varied and complementary conclusions from the different models. The study has making efficiency value analysis, and has established a return to scale to compare the technical efficiency value with the scale efficiency value, with the lesser of the two indicating the major cause of inefficiency for each container terminal. Moreover, using slack variable analysis, the study 
has provided useful information that indicates how relatively inefficient container terminals can improve their efficiency.

Table 6 Projection analysis results

\begin{tabular}{|c|c|c|c|c|}
\hline \multirow{2}{*}{ Terminals } & \multicolumn{4}{|c|}{ Inputs } \\
\hline & $\begin{array}{l}\text { Yard area } \\
\text { per berth }\end{array}$ & $\begin{array}{l}\text { QC per } \\
\text { berth }\end{array}$ & $\begin{array}{l}\text { TC per } \\
\text { berth }\end{array}$ & $\begin{array}{l}\text { YT per } \\
\text { berth }\end{array}$ \\
\hline \multicolumn{5}{|l|}{ Busan } \\
\hline KBCT & $162,750.0$ & 4.0 & 19.0 & 24.0 \\
\hline HBCT & $125,745.5$ & 2.8 & 9.2 & 14.2 \\
\hline INTERGIS & $129,400.0$ & 2.8 & 6.8 & 12.6 \\
\hline Hanjin & $96,000.0$ & 2.0 & 6.0 & 10.0 \\
\hline UTC & $74,000.0$ & 2.5 & 6.5 & 11.5 \\
\hline \multicolumn{5}{|l|}{ Gwangyang } \\
\hline KIT2-2 & $105,535.7$ & 2.3 & 7.9 & 12.0 \\
\hline KX3-1 & $106,509.2$ & 1.8 & 5.0 & 7.6 \\
\hline GICT1 & $103,151.8$ & 2.2 & 7.4 & 11.5 \\
\hline DBE2-1 & $175,600.0$ & 2.0 & 3.8 & 4.0 \\
\hline \multicolumn{5}{|l|}{ Incheon } \\
\hline ICT & $68,886.0$ & 3.0 & 6.5 & 7.0 \\
\hline SGCT & $122,273.0$ & 1.5 & 3.5 & 4.0 \\
\hline \multicolumn{5}{|l|}{ Ulsan } \\
\hline JUCT & $84,275.0$ & 3.0 & 7.0 & 7.0 \\
\hline \multicolumn{5}{|l|}{ Pyeongtaek } \\
\hline PCTC & $96,000.0$ & 2.0 & 6.0 & 10.0 \\
\hline Average & $111,548.20$ & 2.5 & 7.3 & 10.4 \\
\hline \multirow[b]{2}{*}{ Terminals } & \multicolumn{2}{|c|}{ Inputs } & \multicolumn{2}{|c|}{ Output } \\
\hline & $\begin{array}{l}\text { Berth } \\
\text { Length }\end{array}$ & $\begin{array}{l}\text { Water } \\
\text { depth }\end{array}$ & \multicolumn{2}{|c|}{$\begin{array}{c}\text { Throughput per } \\
\text { berth }\end{array}$} \\
\hline \multicolumn{5}{|l|}{ Busan } \\
\hline KBCT & 350.0 & 15.0 & \multicolumn{2}{|c|}{$768,459.0$} \\
\hline HBCT & 286.5 & 12.6 & \multicolumn{2}{|c|}{$475,349.0$} \\
\hline INTERGIS & 289.4 & 12.5 & \multicolumn{2}{|c|}{$420,594.0$} \\
\hline Hanjin & 240.0 & 11.0 & \multicolumn{2}{|c|}{$355,991.0$} \\
\hline UTC & 300.0 & 13.4 & \multicolumn{2}{|c|}{$279,569.0$} \\
\hline \multicolumn{5}{|l|}{ Gwangyang } \\
\hline KIT2-2 & 255.7 & 11.6 & \multicolumn{2}{|c|}{$414,915.0$} \\
\hline KX3-1 & 225.4 & 11.0 & \multicolumn{2}{|c|}{$219,503.4$} \\
\hline GICT1 & 251.8 & 11.4 & \multicolumn{2}{|c|}{$400,184.0$} \\
\hline DBE2-1 & 390.0 & 15.5 & \multicolumn{2}{|c|}{$51,638.0$} \\
\hline \multicolumn{5}{|l|}{ Incheon } \\
\hline ICT & 300.0 & 14.0 & \multicolumn{2}{|c|}{$172,448.0$} \\
\hline SGCT & 203.5 & 11.0 & \multicolumn{2}{|c|}{$14,772.0$} \\
\hline \multicolumn{5}{|l|}{ Ulsan } \\
\hline JUCT & 220.0 & 13.0 & 169 & 52.0 \\
\hline Pyeongtaek & & & & \\
\hline PCTC & 240.0 & 11.0 & 355 & 91.0 \\
\hline Average & 273.3 & 12.5 & 315 & 35.8 \\
\hline
\end{tabular}

Empirical results reveal that substantial waste exists in the production process of the Korean container terminals. For example, the average efficiency of container terminals using the DEA-CCR model amounts to 0.663. This indicates that, on average, the container terminals under study can dramatically increase the level of their outputs by 1.5 times as much as their current level while using the same inputs.

Empirical results also reveal that the container terminals under the study were found to exhibit a mix of increasing and constant returns to scale at current levels of output. This indicates that, the scales of major container terminals are not saturated. Such information is particularly useful for terminal managers or policy makers to decide on the scale of production.

In conducting the research, some limitations are found as follows: in the DEA analysis, the output variables measure various organizational objectives, such as productivity and customer response. In applying DEA analysis to container terminals, suitable productivity indicators that could be considered for evaluation of terminal operations include: throughput, berth occupancy rate and number of vessel arrivals. The input variables in DEA analysis are various resources such as facility, equipment, technology, business, working time capital. In the case of terminal operations, piers, land, carrying equipment and facility capacity are suitable for consideration as possible input variables. However, the selection of suitable input variables and output variables for this study of DEA analysis depended on data availability (duplication, difficult measurement) and correlations among these variables (similar performance, no difference). On this basis, one output variable (throughput per berth) and six input variables (yard area per berth, quay crane per berth, terminal crane per berth, yard tractor per berth, berth length and water depth) have been chosen. Moreover, although applying data on a range of years can facilitate the acquisition of more reliable results and over time, but the data collection is too difficult to complete on thirteen Korean container terminals. Therefore, the objects of this study just consider the data of 2008 year.

Second, although DEA is an effective management tool, but the efficiency value obtained by DEA model is a relative value rather than an absolute value. The evaluation results are dependent on the selected group of DMUs, and the sequence and allocation of efficiency values that are acquired will therefore vary as the composition of the DMUs change. If new data of other year are included into the original model, the efficiency values of existing terminals would be different.

\section{References}

[1] Avriel, M., Penn, M., and Shpirer, N., (2000), "Container ship stowage problem: complexity and connection to the colouring of circle graphs", Discrete Applied Mathematics 103, 271 - 279 .

[2] Andersen, P. and Petersen, N. C., (1993) "A procedure for ranking efficient units in data envelopment 
analysis", Management Science, 39, 1261 - 1264.

[3] Banker, R. D., Charnes, A. and Cooper, W. W., (1984), "Some models for estimating technical and scale inefficiencies in data envelopment analysis", Management Science, 30, 1078 - 1092.

[4] Barros, C. P., and Athanassiou, M. (2004) "Efficiency in European seaports with DEA: Evidence from Greece and Portugal", Maritime Economics and Logistics, 6(2), $122-140$.

[5] Chu, C., and Huang, W., (2002), "Aggregate crane handling capacity of container terminals: the port of Kaohsiung", Maritime Policy and Management 29 (4), $341-350$.

[6] Charnes, A., Cooper, W. W. and Rhodes, E., (1978), "Measuring the efficiency of decision making unit", European Journal of Operational Research, 2, 429 - 444.

[7] Cheon S.H., David E., and Song,D.-W., (2010), "Evaluating impacts of institutional reforms on port efficiency changes: Ownership, corporate structure, and total factor productivity changes of world container ports", Transportation Research Part E 46 (2010) 546 561.

[8] Cullinane, K.P.B., Ji, P., and Wang, T.-F., (2005), "The relationship between privatization and DEA estimates of efficiency in the container port industry", Journal of Economics and Business 57 (2005) 433 - 462

[9] Cullinane K., Wang, T.-F., and Song, D.-W., (2006), "The technical efficiency of container ports: Comparing data envelopment analysis and stochastic frontier analysis", Transportation Research Part A 40 (2006) 354 $-374$

[10] Forsund, F.R., Lovell, C. A. K. and Schmidt, P., (1980), "A survey of frontier production functions and their relationship to efficiency measurement", Journal of Econometrics, 13, 5 - 25.

[11] Forsund, F.R., and Sarafoglou, N., (2002), "On the origins of data envelopment analysis", Journal of Productivity Analysis 17, 23 - 40.

[12] Itoh, H. (2002), "Efficiency changes at major container ports in Japan: A window application of data envelopment analysis", Review of Urban and Regional Development Studies, 14(2), 133 - 152.

[13] Kim, K.H., (1997), "Evaluation of the number of rehandles in container yards", Computers and Industrial Engineering 32 (4), $701-711$.

[14] Kim, K.H., and Bae, J.W., (1998), "Re-marshaling export containers in port container terminals", Computers and Industrial Engineering 35 (3/4), 655 - 658.
[15] Kim, K.H., and Kim, H.B., (1998), "The optimal determination of the space requirement and the number of transfer cranes for import containers", Computers and Industrial Engineering 35 (3/4), 427 - 430.

[16] Kim, K.H., and Kim, K.Y., (1999), "An optimal routing algorithm for a transfer crane in port container terminals", Transportation Science 33 (1), 17 - 33.

[17] Le-Griffin, H. D., and Murphy, M., (2006), "Container terminal productivity: experiences at the ports of Los Angeles and Long Beach"

[18] Lin, L. C. and Tseng, C. C., (2007), "Operational performance evaluation of major container ports in the Asia-Pacific region", MARIT. POL. MGMT. DECEMBER 2007 VOL. 34, NO. 6, 535 - 551.

[19] Liu, Z., (1995), "The comparative performance of public and private enterprises: the case of British ports", Journal of Transport Economics and Policy 29 (3), 263 $-274$.

[20] Robinson, D., (1999), "Measurements of Port Productivity and Container Terminal Design: A Cargo Systems Report. IIR Publications, London"

[21] Roll, Y., \& and Hayuth, Y., (1993), "Port performance comparison applying data envelopment analysis (DEA)", Maritime Policy and Management, 20(2), 153 - 161.

[22] Song, D. W., Cullinane, K. P. B., and Wang, T.F., (2003), "An application of DEA window analysis to container port production efficiency" In International association of maritime economists annual conference.

[23] Tongzon, J., and Heng, W., (2005), "Port privatization, efficiency and competitiveness: some empirical evidence from container ports (terminals)", Transportation Research A: Policy and Practice 39 (5), 405 - 424.

[24] Wilson, I.D., and Roach, P., (2000), "Container stowage planning: a methodology for generating computerised solutions", Journal of the Operational Research Society 51 (11), $248-1255$.

Received 30 September 2010

Revised 23 December 2010

Accepted 23 December 2010 